\begin{tabular}{ll}
\hline \hline MINING AND METALLURGY INSTITUTE BOR & ISSN: 2334-8836 (Štampano izdanje) \\
UDK: 622 & ISSN: 2406-1395 (Online) \\
\hline \hline & \\
\end{tabular}

Slavica R. Mihajlović, Živko T. Sekulić, Dragan S. Radulović, Vladimir D. Jovanović*

\title{
INVESTIGATION THE CALCITE HYDROPHOBISATION OF DIFFERENT GRAIN SIZES ${ }^{* * *}$
}

\begin{abstract}
This paper presents the investigations of possibility of calcite hydrophobisation. Two samples of calcite of different size classes from the site "Dobar kamen", Arandjelovac, Serbia, were used in the experimental work. Modifying the surface of calcite was carried out by stearic acid with "dry" method. Concentrations of stearic acid in the modifying method were as follows: 0.3, 0.5, 0.8, 0.9, 1, 2, 2.5, 3 and 4\%. The results showed that a complete hydrophobicity (Io=99.9\%) of calcite sample with the medium diameter $\left(d_{50}\right) 10.87 \mu \mathrm{m}$ was achieved at concentration of stearic acid of $0.8 \%$, while for the sample with the mean grain diameter $\left(d_{50}\right)$ of $29.14 \mu \mathrm{m}$, it was achieved at concentration of stearic acid of $3 \%$. These results were confirmed by the microscopic analysis.
\end{abstract}

Keywords: calcite, stearic acid, degree of coating, grain-size distribution

\section{INTRODUCTION}

Limestone is a sedimentary carbonate rock that is built of calcite as a dominant mineral, with a slight presence of aragonite, as well as the other minerals that represent impurities [1]. Calcite and aragonite are two polymorphic forms of $\mathrm{CaCO}_{3}$. By chemical composition, calcite is $\mathrm{CaCO}_{3}$, hardness per Mohs 3 and very brittle. Density of pure mineralis $2.72 \mathrm{kgm}^{-3}$, and if it contains impurities, density varies from 2.7 to $2.85 \mathrm{kgm}^{-3}$, [2]. Limiting factor in the application of limestone in certain industries (eg. as filler in the polymer industry) is its hydro-philic surface. Using the methods of surface calcite modifying by organic modifiers, type of surfactants, it is possible to convert its hydrophilic surface into hydrophobic $[3,4]$. As a measure of the achieved surface hydrophobicity of calcite, the degree of coating was taken that was presented by the group of authors in their works [5, 6, 7].

\section{EXPERIMENTAL PART}

\section{Materials and Methods}

Investigations, presented within this paper, were carried out on a sample of limestone from the deposit "Dobar kamen", Arandjelovac, Serbia. Two fractions were used with the following mean grain diameter $\left(\mathrm{d}_{50}\right): 10.87 \mu \mathrm{m}$ and $29.14 \mu \mathrm{m}$. The results

\footnotetext{
* Institute for Technology of Nuclear and Other Mineral Raw Materials, P. O. Box 390, 86 Franshet d'Esperey St., 11000 Belgrade, Serbia, e-mail address: s.mihajlovic@itnms.ac.rs *** This paper is the result of research on the Project TR 34013 titled "Development of Technological Processes for Obtaining of Ecological Materials Based on Nonmetallic Minerals", and the Project TR 34006 titled "Mechanochemical Treatment Under Insufficient Mineral Resources", funded by the Ministry of Education, Science and Technological Development of the Republic of Serbia for the period 2011-2014.
} 
for a fraction of $25.19 \mu \mathrm{m}$, which was an integral part of these tests, the authors published before [8]. Modifying the surface of calcite was carried out by stearic acid $\mathrm{CH}_{3}\left(\mathrm{CH}_{2}\right)_{16} \mathrm{COOH}$ - content of stearic acid: $0.3 ; 0.5 ; 0.8 ; 0.9 ; 1 ; 2 ; 2.5 ; 3$ and $4 \%$.

Modifying of calcite. It was done using so called "dry" method (without presence of water). Nine samples of $200 \mathrm{~g}$ were sampled where the certain concentration of stearic acid was added. A vibro mill was used with ring operating elements, model "MN 954/3", manufacturer "KHD Humboldt WEDAG"Germany. Device operates discontinuously in the air environment. Modifying time is 7 minutes at temperature of $70^{\circ} \mathrm{C}$.

Chemical composition. $\mathrm{CaO}$ content was determined by the volumetric method, while the content of $\mathrm{SiO}_{2}$ and loss by calcination $\left(900^{\circ} \mathrm{C}\right)$ was determined by the gravimetric method (JUS B.B8. 070). Atomic absorption spectrophotometer, type "Perkin Elmer Analyst 703 300", was used for determining $\mathrm{Al}_{2} \mathrm{O}_{3}, \mathrm{Fe}_{2} \mathrm{O}_{3}, \mathrm{MgO}, \mathrm{Na}_{2} \mathrm{O}$ and $\mathrm{K}_{2} \mathrm{O}$.

Mineralogical composition. Qualitative mineralogical analysis was carried out under a polarizing microscope for rejected and transmitted light, brand "JENAPOL", company Carl Zeiss Jena, using the immersion method (immersion xylene) with qualitative identification of present minerals. Magnifition of lens is from 3.2 to $50 \mathrm{X}$. Binocular magnifies is of the Leitz Wetzlar company. System for microphotography "STUDIO PCTV" (Pinnacle Systems).

X-ray diffraction analysis. The XRD samples were obtained on a Philips PW-1710 automated diffractometer. JCPDS (Joint Committee on Powder Diffraction Standards) base was used to identify minerals.

Infrared spectroscopy (IC). Infrared spectra were recorded on apparatus
"Perkin Elmer 983 G", the range of 4000$250 \mathrm{~cm}^{-1}$.

Grain-size distribution. Grain-size distribution of limestone was determined by "Cyclosizer", manufacturer "Warmen". The mass of sample for determining the grainsize distribution is $30 \mathrm{~g}$.

Determining of coating degree. A method, presented in the works of a group of authors, was used to determine a coating degree $[5,6,7]$. The method consists in the following: $10 \mathrm{~g}$ of modified calcite is submerged in $100 \mathrm{ml}$ of distilled water with periodical stirring with a glass rod. After 10 min of standing, the floating fraction and sinking fraction are clearly observed. The floating fraction and sinking fraction were dried at $60^{\circ} \mathrm{C}$, and measured. The form 1 can be applied for calcuting the coating degree Io:

$$
\mathrm{I}_{\mathrm{o}}=\frac{\mathrm{m}_{\mathrm{p}}}{\mathrm{m}_{\mathrm{p}}+\mathrm{m}_{\mathrm{t}}} \cdot 100 \%
$$

where:

$\mathrm{I}_{\mathrm{o}}$ - coating degree, $\%$;

$\mathrm{m}_{\mathrm{p}}$ - mass of floating fraction, $\mathrm{g}$;

$\mathrm{m}_{\mathrm{t}}$ - mass of sinking fraction, $\mathrm{g}$.

\section{RESULTS AND DISCUSSION}

\section{Characterization the Starting Sample of Limestone from the Deposit "Dobar kamen"}

A detailed chemical and mineralogical composition and X-ray diffraction analysis was given by the authors in an earlier published report [4] (dominated by calcite and the $\mathrm{CaO}$ content is $55.43 \%$ ).

Infrared spectroscopy. Infrared spectroscopic analysis was carried out on the starting sample of limestone, and the resulting infrared spectrum is shown in Figure 1. 


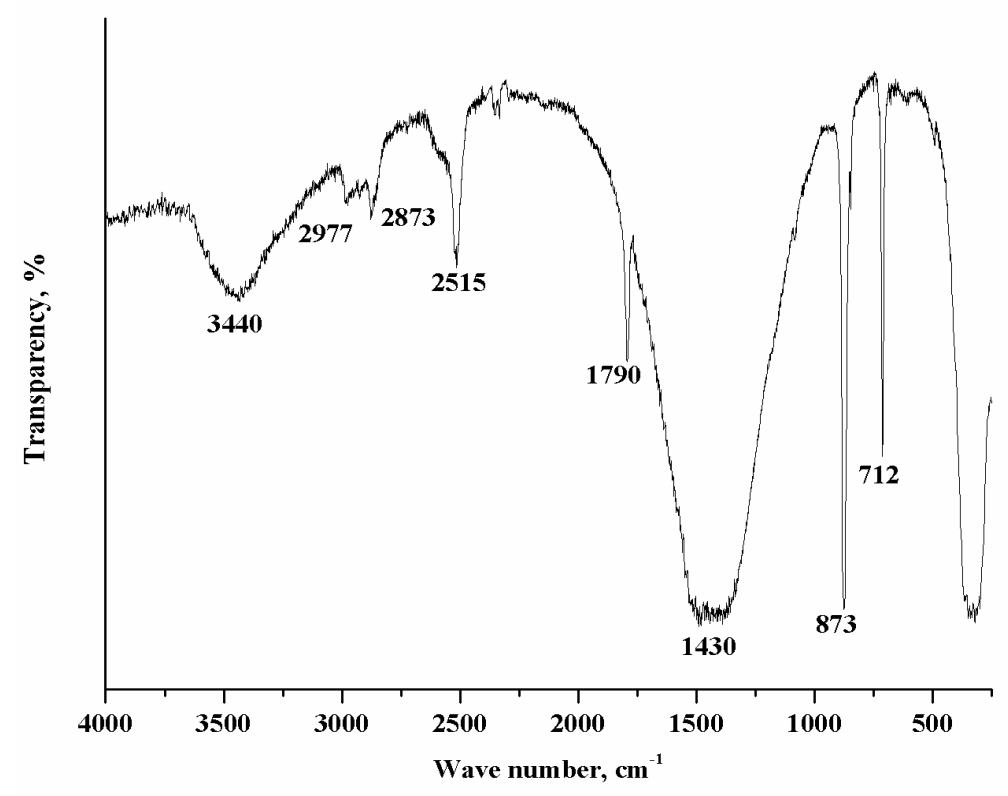

Figure 1 Infrared spectrum starting sample of calcite "Dobar kamen"

Characteristic strips for calcite are observed in the infrared spectrum of starting limestone sample, thus confirming the results obtained by the X-ray diffraction that calcite is the primary mineral in sample. The strips of various intensity appear in the area of wave numbers of $3000 \mathrm{~cm}^{-1}$ to $700 \mathrm{~cm}^{-1}$. The carbonate functional group in calcite is planar (space group $\mathrm{D}_{3 \mathrm{~h}}$ ), and as a non-linear with the number of atoms $\mathrm{N}=4$ has $3 \mathrm{~N}-6=6$ fundamental vibrations, out of which $\mathrm{N}-1=3$ as valence. Symmetrical valence vibration 1 is infrared inactive. A broad and strong strip at about $1430 \mathrm{~cm}^{-1}$ is attributed to the asymmetrical valence vibration of 3 , which is a double degenerated ( $3 \mathrm{a}$ and $3 \mathrm{~b}$ ). A sharp strip at $873 \mathrm{~cm}^{-1}$ belongs to the deformation vibration 2 of the planar carbonate group. Also, ${ }_{4}$ is a deformation one by type, double degenerated vibration ( $4 \mathrm{a}$ and ${ }_{4 \mathrm{~b}}$ ), for which the strip at $709 \mathrm{~cm}^{-1}$ is characteristic in spectrum in Figure 3. Generally, 3 strips occur instead of 6 in calcite spectrum, which belong to the basic vibrations 2,3 and 4 , since 1 IC is inactive, and 3 and 4 are double degenerated. In addition to the strips of fundamental vibrations, the strips of the sum and high harmonics, i.e. the strips of upper tones (overtones) also appear in the spectrum [9]. Thus, two strips of low intensity at 2977 and $2873 \mathrm{~cm}^{-1}$, strips of upper tone $\left(2_{3}\right)$ of fundamental valence 3 vibration of carbonate functional group are observed in the spectrum of starting samples, and which occur in the range from 2980 to $2830 \mathrm{~cm}^{-1}$ [10]. According to Osman and Suter [11], the strip at $2515 \mathrm{~cm}^{-1}$ belongs to bicarbonate ion, $\mathrm{CO}_{3} \mathrm{H}^{-}$, on calcite surface. However, according to Gilbert and associates [9], that strip is the strip of the sum $\left({ }_{1}\left(1083 \mathrm{~cm}^{-1}\right)+\right.$ 3) of fundamental vibrations of carbonate group. The strip at $1790 \mathrm{~cm}^{-1}$ is also the strip of the sum, that is $(1+2)$ of the fundamental vibrations of ion [12]. The broad strip at about $3440 \mathrm{~cm}^{-1}$ originates 
from the valence vibrations of water molecules that are present in the sample, connected to each other by the hydrogen bonds.

Grain-size distribution: Figures 2 and 3 show curves of particle size distribution of the limestone starting samples with mean grain diameter $\left(\mathrm{d}_{50}\right): 10.87 \mu \mathrm{m}$ and $29.14 \mu \mathrm{m}$ as follows: direct curve (1), cumulative curve of oversize (2) and cumulative curve of undersize (3). Also, the upper limit coarseness (ulc) was read for samples using the cumulative curve of oversize.

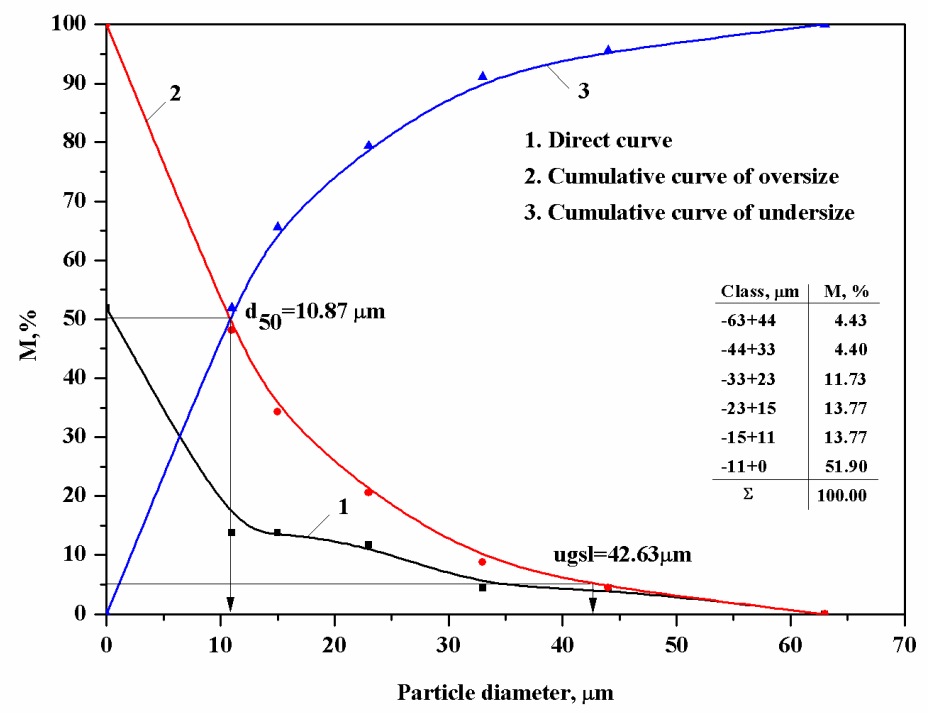

Figure 2 Curves of particle size distribution of limestone $d_{50}=10.87 \mu \mathrm{m}$

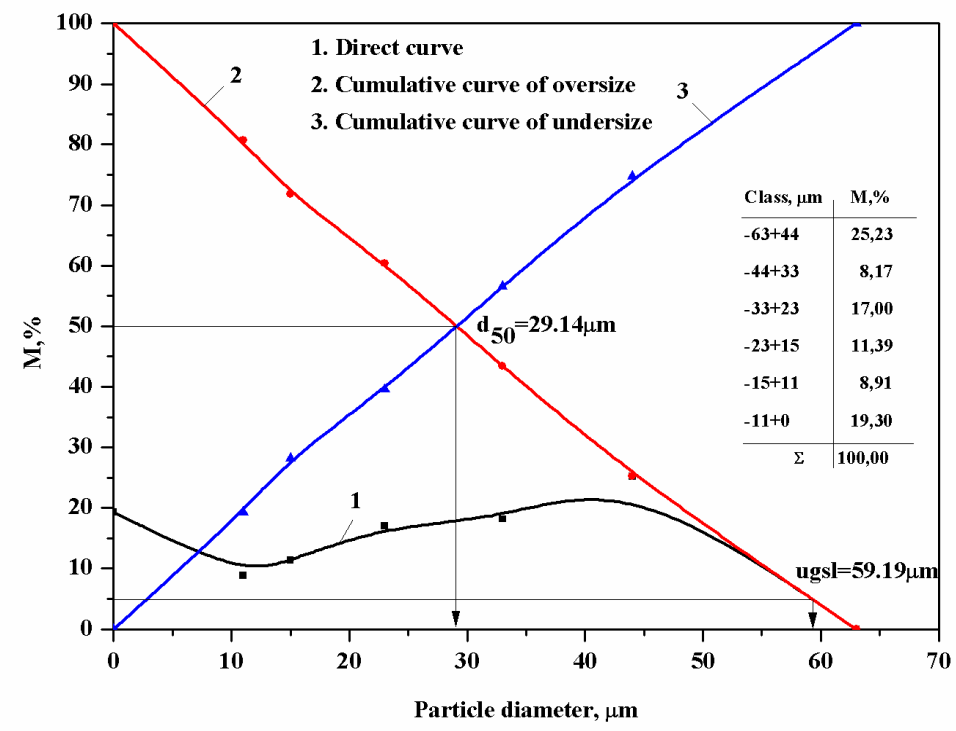

Figure 3 Curves of particle size distribution of limestone $d_{50}=29.14 \mu \mathrm{m}$ 


\section{Coating Degree of Modified Calcite}

Limestone modifying actually means calcite modifying as the main mineral. In order to monitor the results of calcite modifying using stearic acid with "dry" method, and achievement the satisfactory surface hydrophobicity, a coating degree was determined on all modified samples according to the form 1 . Values of coating degree for all three size classes of calcite at various concentrations of stearic acid are shown in Table 1; the comparative graphs in Figure 4.

Table 1 Coating degree of modified calcite

\begin{tabular}{|c|c|c|}
\hline $\begin{array}{c}\text { Concentration of stea- } \\
\text { ric acid, \% }\end{array}$ & $\mathbf{d}_{\mathbf{5 0}}=\mathbf{1 0 . 8 7} \boldsymbol{\mu m}$ & $\mathbf{d}_{\mathbf{5 0}}=\mathbf{2 9 . 1 4} \boldsymbol{\mu m}$ \\
\cline { 2 - 3 } & $\mathbf{I o}, \boldsymbol{\%}$ & $\mathbf{I o}, \boldsymbol{\%}$ \\
\hline 0.3 & 92.6 & 25.72 \\
\hline 0.5 & 96.6 & 42.78 \\
\hline $\mathbf{0 . 8}$ & $\mathbf{9 9 . 9}$ & 69.08 \\
\hline 0.9 & 99.9 & 68.89 \\
\hline 1.0 & 99.9 & 71.2 \\
\hline 2.0 & 99.9 & 73.4 \\
\hline 2.5 & 99.9 & 80.2 \\
\hline 3.0 & 99.9 & 99.9 \\
\hline 4.0 & 99.9 & 99.9 \\
\hline
\end{tabular}

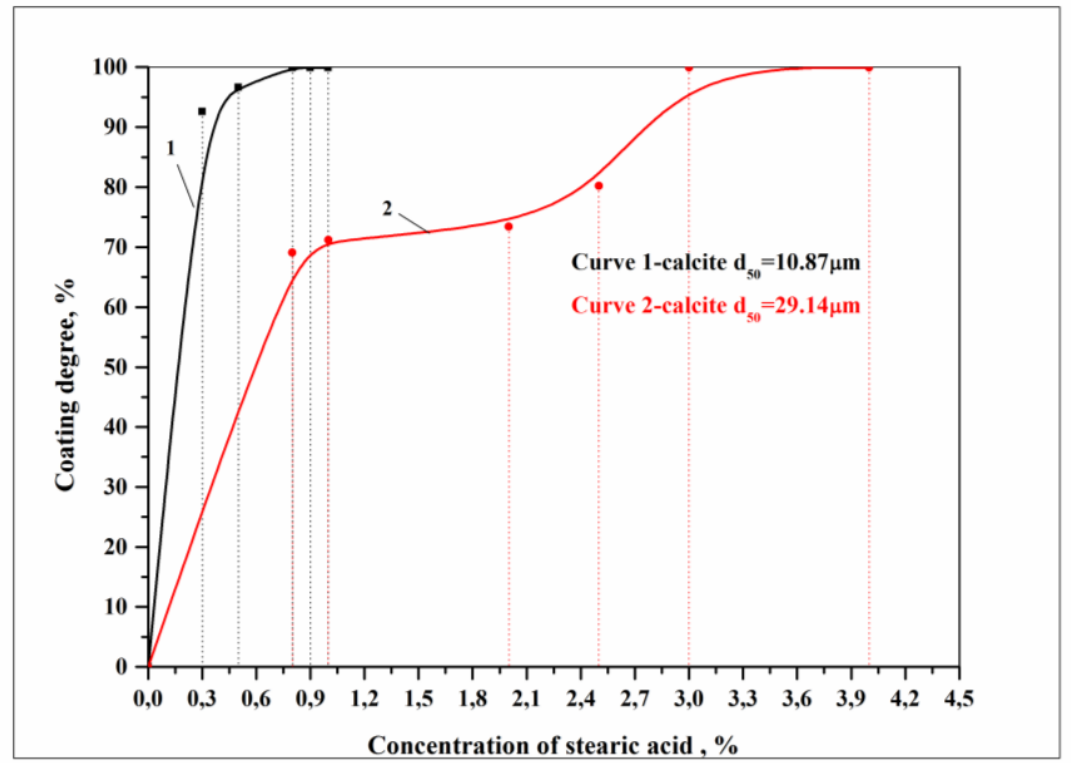

Figure 4 Comparative graphs of coating degree of modified calcite samples 
Coating degree of $99.9 \%$, in calcite $\mathrm{d}_{50 \mathrm{r}}=10.87 \mu \mathrm{m}$, was achieved at concentration of stearic acid of $0.8 \%$, while in calcite $\mathrm{d}_{50}=29.14 \mu \mathrm{m}$ it was achieved at concentration of $3 \%$. By further increasing the concentration of stearic acid in the modifying procedure, the coating degree remains unchanged. This indicates that the orientation of hydrocarbon chains was not changed in the adsorbed layer with an increase of stearic acid concentration available for adsorption. Adsorption was always such that the molecule of surfactant, in this case stearic acid, was kept an orientation of its hydrophobic portion (hydrocarbon chain) in the opposite from calcite surface. As coating degree can be taken as a measure of hydrophobicity of the obtained products [13], the results indicate that total hydrophobicity of calcite surface with "dry" method was achieved at stearic acid concentration of $0.8 \%$ for sample $\mathrm{d}_{50}=10.87 \mu \mathrm{m}$, and at concentration of $3 \%$ for sample $d_{50}=29.14 \mu \mathrm{m}$.

\section{X-Ray Diffraction Analysis of Modified Calcite}

In order to monitor the structural changes of calcite occurring during modifying, the X-ray diffraction analysis was carried out on fully modified, or completely hydrophobic samples. Comparative X-ray diffractograms of calcite powder are shown in Figure 5.

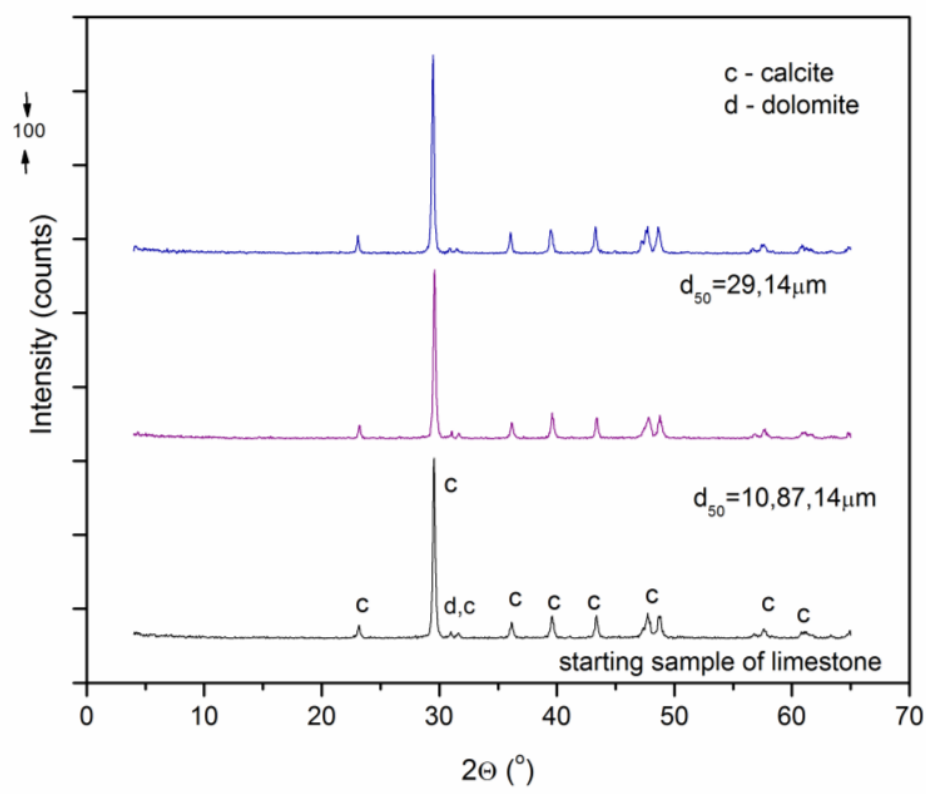

Figure $5 X$-ray diffractograms of powders of coated calcites $d_{50}=10.87 \mu \mathrm{m}$ and $d_{50}=29.14 \mu \mathrm{m}$

Calcite upon modifying with stearic acid and achieving a complete hydrophobicity retains the basic structure irrespective of size class, which is modified. These results indicate that the adsorption process occurs on the phase boundaries. It can be seen by ana- lysis of the fundamental diffraction peaks of calcite that there are no changes in their diffraction angles $(\theta)$ and intensities, and that there was no systematic displacement of reflections and amorphization after adsorption of stearic acid. 


\section{Infrared Spectroscopy of the Starting Sample and Modified Sample}

The infrared spectra of the starting sample and modified calcite sample of the largest size classes $d_{50}=29.14 \mu \mathrm{m}$ are shown in Figure 6. Compared to the typical strips of starting calcite (spectrum 1), it is observed that there was no change in the position and intensity of most strps in modified calcite $d_{\text {sr }}=29.14 \mu \mathrm{m}$ (spectrum
2). In modified sample $d_{s r}=29,14 \mu \mathrm{m}$ (spectrum 2), in the range from 3000 to $2800 \mathrm{~cm}^{-1}$, the strips are observed at 2950 , 2918,2873 and $2852 \mathrm{~cm}^{-1}$, originating from valence vibrations of $\mathrm{C}-\mathrm{H}$ bonds in $-\mathrm{CH}_{3}$ and $-\mathrm{CH}_{2}$ groups of hydrocarbon chains of the adsorbed organic component [1113].

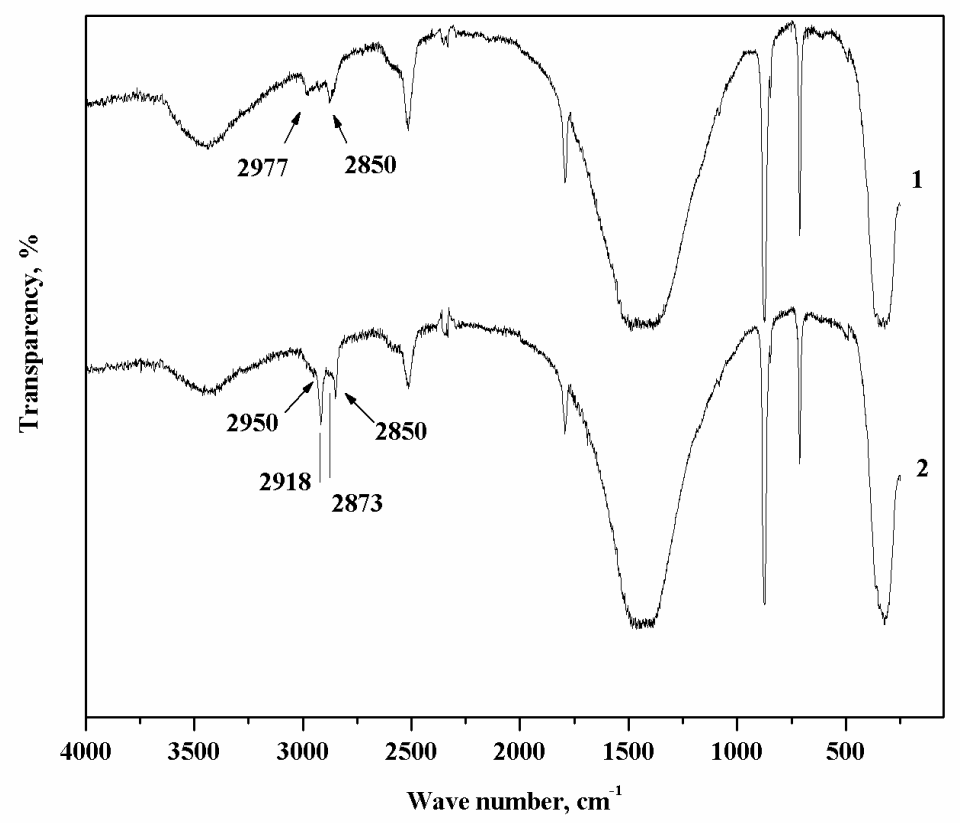

Figure 6 Comparative infrared spectra:

1) starting sample of calcite; 2) sample $d_{50}=29.14 \mu \mathrm{m}$

When the wave numbers of IC strips of $\mathrm{C}-\mathrm{H}$ vibrations in the spectrum of 2 are compared to the strips that Osman and Suter [11] observed in the spectrum of crystalline stearic acid (2954, 2916, 2872 and $2849 \mathrm{~cm}^{-1}$ ), it is seen that the strips in calcite, treated with stearic acid, are slightly displaced towards higher values, except the strip corresponding to the asymmetrical C$\mathrm{H}$ vibration of $-\mathrm{CH}_{3}$ group $\left(2950 \mathrm{~cm}^{-1}\right)$.
This displacements towards smaller wave numbers as well as poorly expressed strips of valence $\mathrm{C}-\mathrm{H}$ vibrations in $-\mathrm{CH}_{3}$ group, indicate a greater representation of the Gauch conformation and sloping orientation of the hydrocarbon chain regarding to the calcite surface, i.e. lower density of "packing" the hydrocarbon chains in the adsor-bed layer of modified calcite $\mathrm{d}_{\mathrm{sr}}=29.14 \mu \mathrm{m}$. 


\section{Microscopic Analysis of Modified \\ Calcite}

Microphotographs are shown in Figure 7.

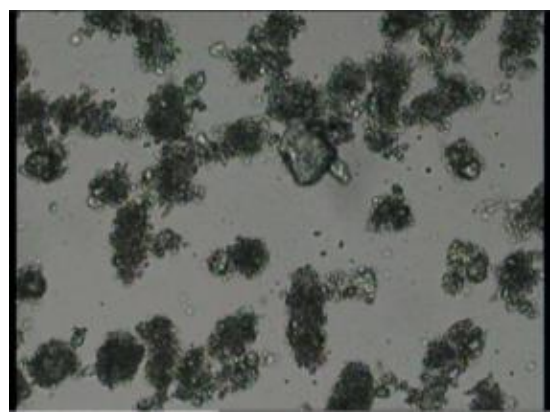

a)

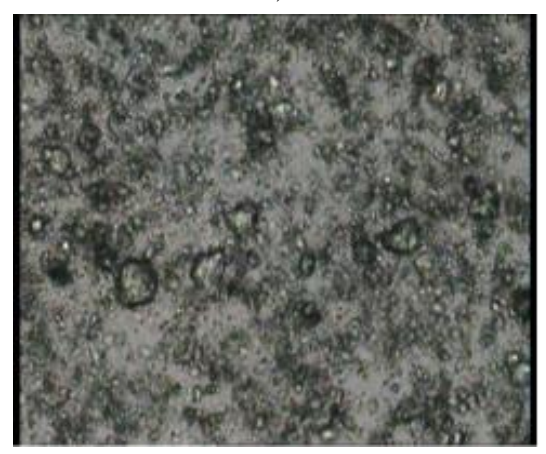

c)

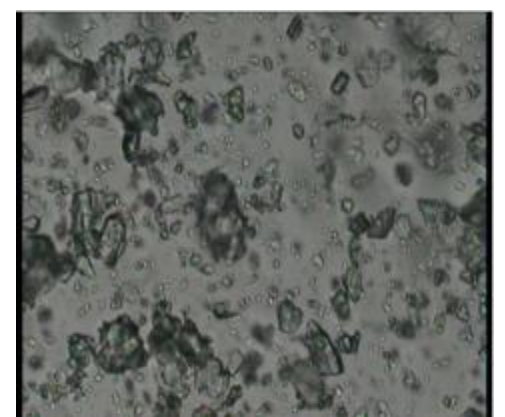

b)

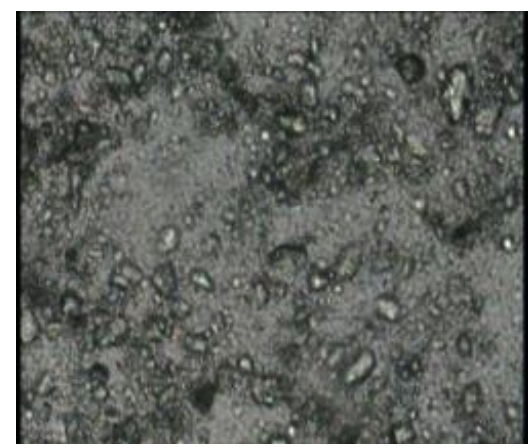

d)

Figure 7 Microphotographs of the starting calcite sample a) $d_{50}=10.87 \mu \mathrm{m}$; b) $d_{50}=29.14 \mu \mathrm{m}$ and modified calcite sample c) $d_{50}=10.87 \mu \mathrm{m}$; d) $d_{50}=29.14 \mu \mathrm{m}$ (magnification 20X)

In microphotographs $7 \mathrm{a}$ i $7 \mathrm{~b}$, free grains of calcite are clearly observed, which have the characteristic interference colors of highorder, what is the feature of uncoated calcite mineral. However, in Figures 7c i 7d showing the microphotographs of sample with the coating degree Io $=99.9 \%$, only the aggregates are observed indicating a complete coating of calcite.

\section{CONCLUSION}

Coating degree increases with increasing the concentration of stearic acid used to modify. However, it can be noted that for the same concentration of stearic acid, different coating degree was achieved in different class sizes. Maximum value of coating degree of $99.9 \%$, in calcite of size class $\mathrm{d}_{50}=10.87 \mu \mathrm{m}$, was achieved at stearic acid concentration of $0.8 \%$, while in calcite of 


\section{REFERENCES}

size classes of $\mathrm{d}_{50}=29.14 \mu \mathrm{m}$ it was achieved at concentration of $3 \%$. Adsorption was always such that the molecule of surfactant, in this case, stearic acid, has kept orientation of its hydrophobic portion opposite to the surface of calcite. The results of microscopic analysis are also consistent with the obtained coating degree of analyzed samples. Namely, the grains having characteristic interface colors of high order were observed in the starting samples which is a characteristic of uncovered calcite mineral, while figures show the micro-photos of sample with the coating degree Io = $99.9 \%$, where aggregates are only observed indicating a complete covering of calcite. The results of X-ray diffraction analysis confirmed that there was no distortion of the crystal calcite structure by modifying method. Infrared spectroscopic analysis has shown that modifying does not change the positions and intensities of the fundamental IC strips, characteristic for calcite, but stronger strips appear in the range from $3000 \mathrm{~cm}^{-1}$ to $2800 \mathrm{~cm}^{-1}$ as well as a number of strips than in the starting sample due to the symmetric and asymmetric valence vibrations of $\mathrm{C}-\mathrm{H}$ bonds of hydrocarbon chain of adsorbed organic component. Poorly expressed IC strips of valence $\mathrm{C}-\mathrm{H}$ vibrations in $-\mathrm{CH}_{3}$ group appear in the modified calcite sample of size class $\mathrm{d}_{\mathrm{sr}}=29.14 \mu \mathrm{m}$ as well as displacement of IC strip corresponding to the asymmetric $\mathrm{C}-\mathrm{H}$ vibration of $-\mathrm{CH}_{3}$ group towards smaller wave numbers as compared to the strip of stearic acid. It has pointed to the increased representation of the Gauch conformation and sloping orientation of the hydrocarbon chain regarding to the surface of calcite, and lower density of "packing" of hydrocarbon chains in the adsorbed layer.
[1] J. Pavlica, D. Draškić, Mineral Processing, Faculty of Mining and Geology, University in Belgrade, 1977 (in Serbian)

[2] S. Janjić, P. Ristić, Mineralogy, Naučna knjiga, Belgrade, 1989 (in Serbian)

[3] S. Mihajlović, Ž. Sekulić, A. Daković, D. Vučinić, V. Jovanović, J. Stojanović, Surface Properties of Natural Calcite Filler Treated with Stearic Acid, Ceram. Silik. 53 (2009) 268-275.

[4] S. R. Mihajlović, A. S. Daković, Ž. T. Sekulić, D. A. Ileš, M. M. Kragović, Surface Adsorption of Stearic Acid of Natural Calcite, Hem. Ind. 63 (2) (2009) 101-106 (in Serbian)

[5] Y. Sheng, B. Zhou, Ch. Wang, X. Zhao, Y. Deng, Z. Wang, In Situ Preparation of Hydrophobic $\mathrm{CaCO}_{3}$ in the Presence of Sodium Oleate, Appl. Surf. Sci. 253 (4) (2006) 1983-1987.

[6] Y. Sheng, B. Zhou, J. Zhao, N. Tao, K. Yu, Y. Tian, Z. Ch. Wang, Influence of Octadecyl Dihydrogen Phosphate on the Formation of Active Super-Fine Calcium Carbonate, J. Colloid Interface Sci. 272 (2) (2004) 326 -329.

[7] Y. F Yang, X. F. Wu, G. Sh. Hu, B. B Wang, Effects of Stearic Acid on Synthesis of Magnesium Hydroxide Via Direct Precipitation, J. Cryst. Growth. 310 (15) (2008). 3557-3560.

[8] S. Mihajlović, Ž. Sekulić, D. Radulović, D. Stevanović, V. Kašić, Hydrophobization of Limestone from the Deposit "Cancar" Arandjelovac by the Use of Stearic Acid, Tehnika, 666 (2015) 943-946. (in Serbian)

[9] M. Gilbert, I. Sutherlan, A. Guest, Characterization of Coated Particulate Fillers, J. Mater. Sci. 35 (2000) 391397. 
[10] E. Fekete, B. Pukánszky, Surface Coverage and its Determination: Role of Acid-Base Interactions in the Surface Treatment of Mineral Fillers, J. Colloid Interface Sci. 194 (1997) $269-275$.

[11] M. A. Osman, U. W. Suter, Surface Treatment of Calcite with Fatty Acids: A Structure and Properties of the Organic Monolayer, Chem. Mater. 14 (2002) 4408-4415.
[12] A. Martínez-Luèvanos, A. Uribe-Salas A. López-Valdivieso, Mechanism of Adsorption of Sodium Dodecylsulfonate on Celestite and Calcite, Min. Eng. 12 (1999) 919-936.

[13] G. Hansen, A. A. Hamouda, R. Denoyel, The Effect of Pressure on Contact Angles and Wettability in the Mica/Water/n-Decane System and the Calcite+Stearic Acid/Water/n-Decane System, Colloids Surf. A. 172 (2000) 7-16. 